\title{
La culture du glaïeul
}

I* Arigatura

Canada

Publication 1229/F

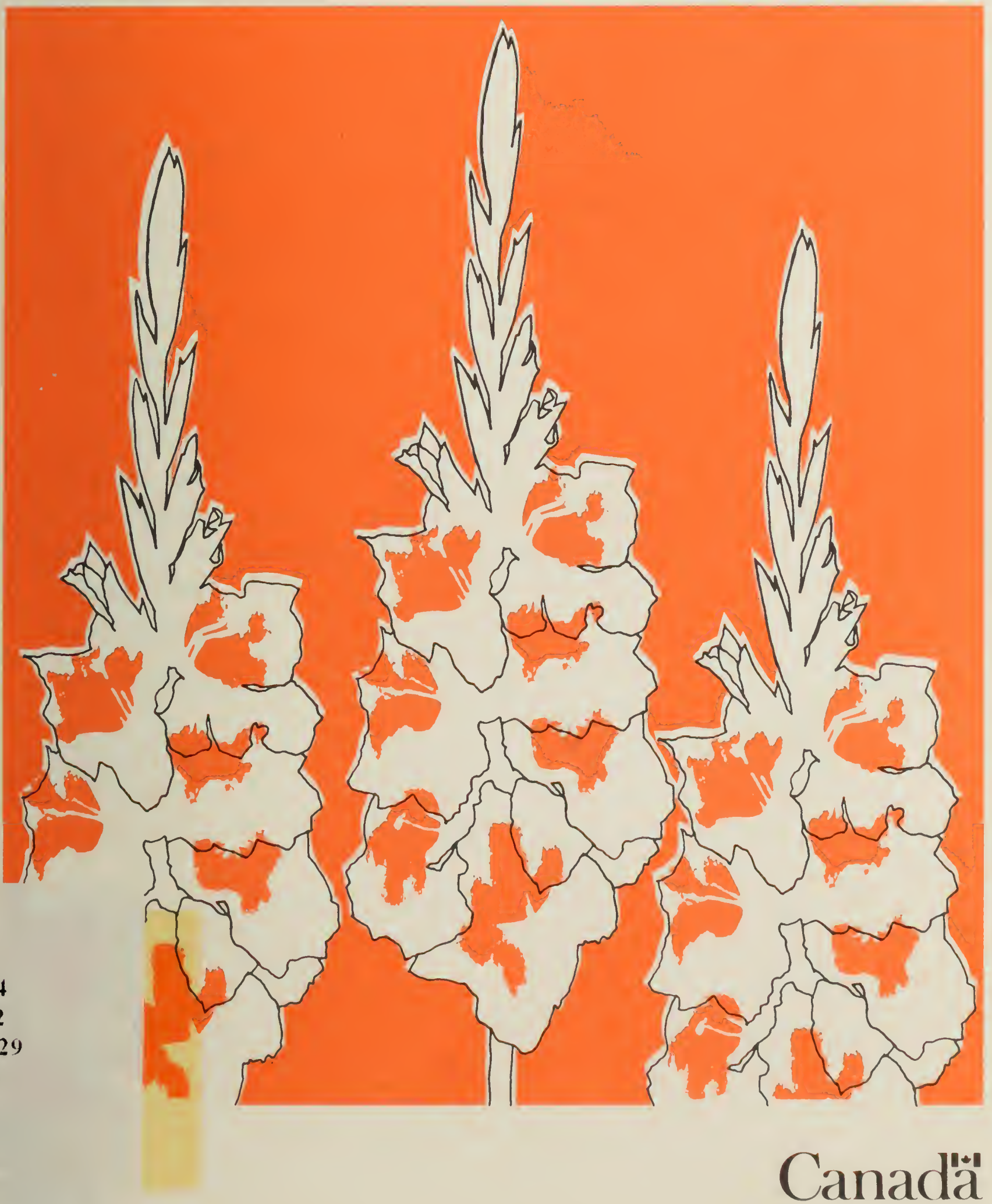


PUBLICATION 1229F, on peut obtenir des exemplaires à la Direction générale des communications, Agriculture Canada, Ottawa K IA $0 \mathrm{C} 7$

(c) Ministre des Approvisionnements et Services Canada 1983

$N^{\circ}$ de cat. A53-1229 1983F ISBN: 0-662-92201-8

Impression 1965 Révision 1983 3M-11:83

Also available in English under the title Growing Gladiolus. 


\section{TABLE DES MATIÈRES}

Introduction 4

Culture 4

Plantation 4

Soins d'été 6

Soins d'automne et d'hiver 8

Classement et terminologie 9

Culture de fleurs destinées aux expositions 9

Insectes et acariens 10

Pucerons 10

Thrips du glaïeul 11

Tétranyque à deux points 12

Taupins 12

Ciron des bulbes 13

\section{Désherbage 13}

Choix de l'herbicide 13

Application de l'herbicide 14

\section{Maladies 14}

Mesures générales de lutte 14

Maladies causées par les bactéries et les champignons 16

Maladies virales 20

Remerciements 21

Noms scientifiques 21 


\section{La culture du glaïeul}

W.C. Lin

Station de recherche et de quarantaine des plantes de Saanichton, Sidney (C.-B.)

\section{INTRODUCTION}

Le glaïeul est une plante recherchée qui s'adapte à une grande variété de climats et de sols. La fleur coupée, d'excellente qualité et aux couleurs attrayantes, occupe un rang enviable aux expositions.

Le glaïeul occupe le dixième rang pour la production de fleurs coupées au Canada. L'Ontario produit chaque année environ un million d'épis (fleurs coupées); le Québec et les autres provinces en produisent environ un quart de million. En outre, les jardiniers amateurs en cultivent chaque année des milliers.

Pour obtenir les meilleurs résultats:

- planter en plein soleil dans un sol fertile et bien drainé;

- arroser abondamment au cours de la saison de croissance;

- protéger les cormus et les plants contre les insectes et les maladies;

- faire sécher les cormus fraîchement déterrés, les traiter au fongicide-insecticide et les entreposer convenablement;

- dans les Prairies et autres régions à courte saison de végétation, planter des variétés de très hâtives à mi-saison, ou faites germer les cormus à l'intérieur avant de les planter.

Plusieurs insectes et maladies peuvent gravement endommager le glaïeul. Le thrips du glaïeul, l'un des insectes nuisibles les plus communs, hiverne sur les cormus, et peut abîmer les fleurs et les feuilles. Le meilleur moyen de lutte est de traiter les cormus ainsi que les plants avant la floraison.

Pour prévenir et combattre les maladies qui s'attaquent aux cormus et aux feuilles, garder les plantations exemptes de mauvaises herbes, alterner les cultures, pulvériser les plantes, trier et traiter les cormus. Détruire les plantes infectées de virus; il n'y a pas de remède.

Consulter votre spécialiste provincial sur la nécessité d'appliquer des pesticides et les méthodes de lutte recommandées.

\section{CULTURE}

\section{Plantation}

\section{Emplacement}

Choisir un emplacement ensoleillé. À l'ombre, les plantes s'étiolent et ne fleurissent pas bien. Garder le sol humide et protéger les glaïeuls contre les grands vents. Le glaïeul se distingue par sa rusticité dans les situations ensoleillées 
chaudes. En revanche, les plants exposés à une courte photopériode, à une faible intensité lumineuse et à des températures fraîches, la nuit, produisent des tiges qui portent un moins grand nombre de bourgeons floraux ou qui en sont complètement dépourvues.

\section{Sol}

Une terre franche friable ou franche sablonneuse de 20 à $25 \mathrm{~cm}$ de profondeur convient le mieux; une terre argileuse est satisfaisante à condition qu'elle soit aérée et bien drainée. Les sols argileux peuvent être améliorés en y ajoutant de la matière organique, notamment de la tourbe, du compost ou du fumier bien décomposé. Préparer le sol plusieurs mois avant la plantation. Un sol légèrement acide ( $\mathrm{pH} 6$ à $6,5)$ est souhaitable.

\section{Fertilisation}

Les besoins en engrais varient selon les conditions météorologiques, les méthodes d'irrigation et le type de sol. Les sols sablonneux doivent être fertilisés souvent, alors que certaines terres franches plus fortes ne nécessitent qu'un faible apport de fumure.

Pour obtenir des plants vigoureux et sains, il faut presque toujours enrichir le sol. Deux applications suffisent habituellement, la première immédiatement avant la plantation et l'autre au début de l'été, à l'apparition des bourgeons floraux. Une analyse du sol par le ministère provincial de l'Agriculture donnera la meilleure indication du type et de la quantité d'engrais à utiliser.

Enfouir l'engrais dans le sillon ou l'étendre en bandes de chaque côté et à quelques centimètres sous les cormus. Une application trop forte peut brûler les racines. L'épandage à la volée est acceptable, mais il en faut alors une plus grande quantité.

\section{Cormus et caïeux}

Les cormus et les caïeux sont les parties souterraines de la plante qui en assurent la reproduction. Le cormus est parfois improprement appelé «bulbe». Les caïeux ou «petits bulbes» sont insérés à la base du nouveau cormus et au-dessus du vieux (fig. 1). Ce sont eux qui assurent la multiplication du cormus de glaïeul.

\section{Calibres}

Les cormus sont classés en trois catégories d'après leur diamètre: gros, plus de $4 \mathrm{~cm}$; moyens, de 3 à $4 \mathrm{~cm}$; et petits, de 1 à $3 \mathrm{~cm}$. Les gros cormus se prêtent le mieux à la culture des fleurs d'exposition et à la floraison hâtive. Les moyens produisent de très beaux épis de fleurs un peu plus petites que celles des précédents et fleurissent plusieurs jours plus tard. Les petits cormus viennent bien dans les régions à longue période de végétation ou lorsqu'ils reçoivent des soins spéciaux dès leur plantation; la plupart fleurissent la première année et produisent surtout des cormus de calibre moyen ainsi que quelques gros. Il faut ordinairement une saison complète pour que les caïeux deviennent de petits cormus. Dans les régions à longue saison de végétation, la plantation échelonnée de lots de cormus de 
calibres différents, à intervalles de 10 jours. donne une période de floraison ininterrompue.

\section{Profondeur et espacement}

Planter les cormus à une profondeur de 8 à $13 \mathrm{~cm}$ selon leur calibre et la texture du sol. Les enfouir plus profondément dans les sols secs à texture légère ainsi que dans les sols meubles ou dans les endroits venteux où les plantes peuvent être renversées.

Espacer de 10 à $15 \mathrm{~cm}$ dans les sillons à deux rangées ou plus et de 3 à $5 \mathrm{~cm}$ dans les sillons à un seul rang. Les sillons doivent être suffisamment éloignés pour qu'on puisse facilement biner, arroser, couper les fleurs et déterrer les cormus.

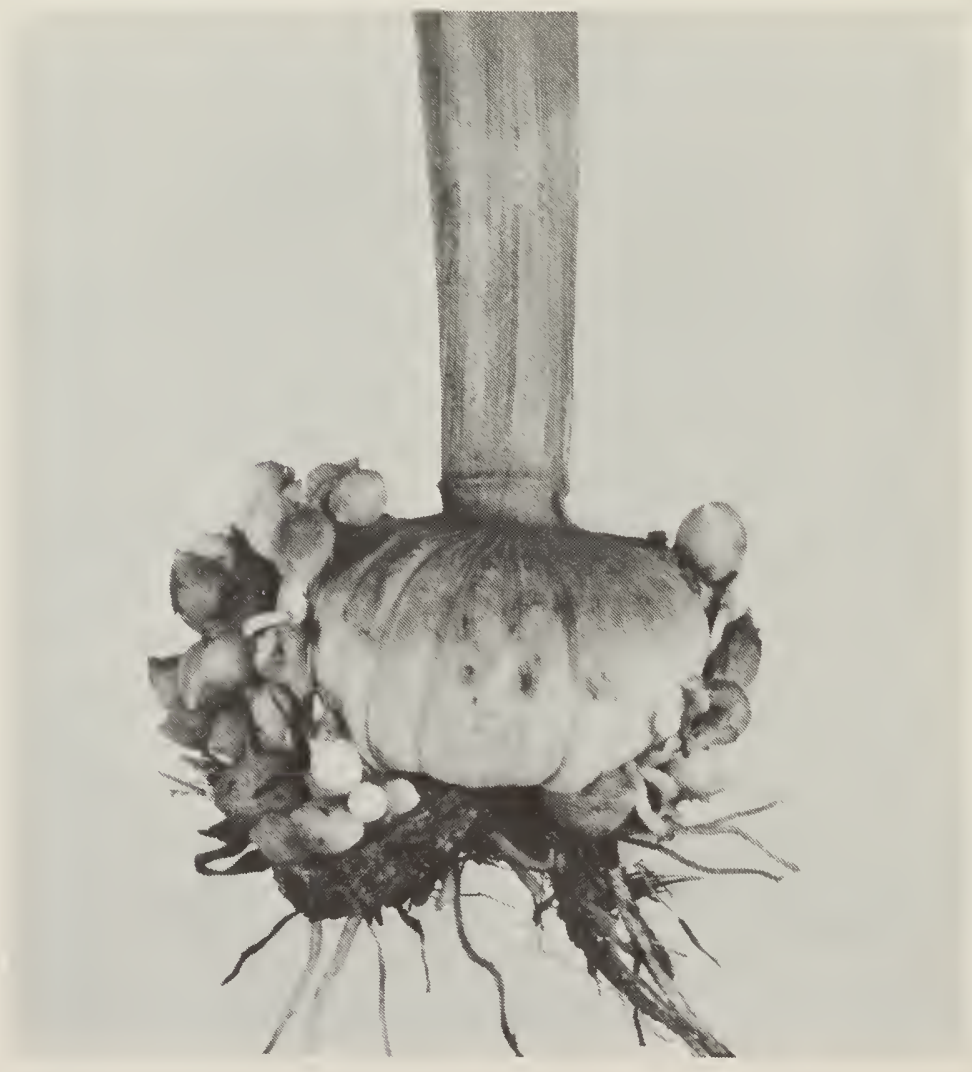

Fig. 1 Nouveau cormus avec vieux cormus et caïeux reliés à la base.

\section{Soins d'été}

\section{Arrosage}

Pour produire des fleurs de première qualité et une quantité suffisante de cormus, les plants ont besoin de beaucoup d'humidité, surtout depuis le moment où ils sortent de terre jusqu'au stade à deux feuilles; ce stade correspond à peu près à la période de formation des bourgeons floraux. Au besoin, irriguer tous les 10 à 14 jours jusqu'à une profondeur de $30 \mathrm{~cm}$; vérifier au moyen d'une tarière ou d'une pelle. 


\section{Paillage}

Le paillage aide à conserver l'humidité. Utiliser de la paille hachée, des résidus séchés de tonte de gazon. de la sciure de bois, de la tourbe horticole ou des fragments de parties ligneuses du lin.

Un paillage est efficace si:

- il retient l'humidité du sol, ce qui dépend de la finesse, de la compacité et de l'épaisseur du paillis. Le paillis de sciure de bois doit avoir une épaisseur de 5 à $10 \mathrm{~cm}$;

- le sol est humide et peut conserver l'humidité. Si le sol est sec, s'il y a peu de pluie et si l'on n'irrigue pas, le paillage est inutile;

- on peut s'en débarrasser à l'automne: incorporer au sol si la quantité de matière organique ajoutée est faible (de 1 à $3 \mathrm{~cm}$ ). Afin de ne pas déranger l'équilibre des éléments nutritifs du sol, n'y incorporer qu'une petite quantité de paillis; brûler ou enlever l'excédent.

\section{Tuteurage}

Les grosses plantes ont besoin de tuteurs, particulièrement si les fleurs sont destinées à une exposition. Les tuteurs en bambou et les attaches pour plantes conviennent parfaitement.

\section{Coupe et conservation des fleurs}

Voici une méthode facile et rapide de couper les fleurs sans endommager les plantes. Insérer la pointe d'un couteau à lame mince dans la tige florale (à travers les feuilles protectrices) et percer. Avec le pouce vis-à-vis et au-dessus du couteau. ramener prestement la tige vers le couteau, et la tordre pour la rompre.

$\mathrm{Si}$ l'on enlève des feuilles en coupant les fleurs, les nouveaux cormus seront plus petits, mais il est impossible de laisser toutes les feuilles intactes dans le cas des fleurs à longues tiges. Lorsqu'on ne cultive les plantes que dans le but de produire des cormus, il faut couper la tige florale dès que l'épi sort du fourreau. particulièrement chez les variétés de mi-saison et les variétés tardives.

Si l'on destine les hampes florales à un usage immédiat, les couper dès l'ouverture des premiers boutons de l'épi. Il est préférable de récolter les fleurs au début de la matinée, lorsqu'elles sont humides et fraîches. Cependant, si les tiges se brisent facilement et que l'on doit en cueillir de grandes quantités, il vaut mieux attendre que les pétales commencent à languir. Les fleurs légèrement flétries se relèvent rapidement une fois placées dans l'eau à la température ambiante et durent aussi longtemps que les fleurs fraîches; il n'y a cependant aucun intérêt à couper des fleurs trop flétries.

C'est à une température variant de 4 à $6^{\circ} \mathrm{C}$ que les fleurs coupées se conservent le mieux; mais il ne faut pas les garder au froid plus d'une semaine si l'on veut qu'elles restent attrayantes plusieurs jours à la température ambiante. Une solution nutritive de survie contenant des sucres et des bactéricides peut prolonger la durée de survie des fleurs coupées de 3 à 5 jours. La qualité de l'eau est également importante à cet égard. Elle doit avoir une faible teneur en sels solubles et ne doit pas contenir de fluorures dissous. 


\section{Soins d'automne et d'hiver}

\section{Récolte des cormus}

Récolter les cormus de 6 à 8 semaines après la floraison ou au cours des deux premières semaines d'octobre. On ne gagne rien à retarder la récolte, même dans les régions où la période sans gel est plus longue. Choisir un jour ensoleillé; ne déterrer que les plants qu’on peut équeuter et faire partiellement sécher en plein air avant la nuit. À l'aide d'un couteau ou d'un sécateur tranchant, couper les tiges et les feuilles à ras de cormus.

\section{Séchage et nettoyage}

Un séchage satisfaisant est essentiel à la conservation des cormus. Sur la côte du Pacifique, où le temps est extrêmement humide lors de la récolte, le séchage est d'importance vitale, probablement plus que n'importe où ailleurs au Canada. Mais même dans les régions plus sèches, il est préférable de faire sécher les cormus avant de les entreposer.

Placer les cormus dans des plateaux à fond grillagé ou à claire-voie et les garder pendant une semaine ou deux dans une pièce où il est relativement facile de régler la température, l'humidité et l'aération. En règle générale, il vaut mieux les garder à $27^{\circ} \mathrm{C}$. À une température variant de: 32 à $35^{\circ} \mathrm{C}$, le séchage est plus rapide et plus parfait, mais aussi plus coûteux. À $21^{\circ} \mathrm{C}$ le séchage est trop lent pour retarder le développement des pourritures d'entrepôt. Cependant, toutes les conditions de séchage qui favorisent la dessiccation des cormus tendent à retarder l'émergence des plantes et à réduire le nombre d'inflorescences hâtives. Lorsque le nouveau cormus se détache facilement, le séchage est presque terminé et il faut commencer le nettoyage. La prolongation du séchage ne fait que rendre les cormus plus difficiles à séparer.

Débarrasser les cormus de toute trace de terre et en détacher les vieux cormus. Il peut être bon d'enlever les pelures sèches afin de découvrir les cormus malades. Immédiatement après avoir nettoyé les cormus, les poudrer abondamment d'un mélange fongicide-insecticide pour les protéger contre les maladies d'entreposage et les insectes, particulièrement les thrips. Les cormus nettoyés doivent rester à $27^{\circ} \mathrm{C}$ de 3 à 7 jours de plus; ce traitement racornit la base des bulbes et les rend résistants aux maladies.

\section{Entreposage}

Pour lever la dormance des cormus déterrés au cours des mois d'été, il faut les entreposer au froid (de 2 à $4^{\circ} \mathrm{C}$ ) pendant 3 à 4 mois. Entreposer les cormus à cette température, en couches minces, sur des plateaux peu profonds, à fond grillagé de préférence. Vérifier de temps en temps s'il y a des maladies ou de l'humidité excessive. Si les cormus sont humides, chauffer la pièce à l'aide d'un appareil de chauffage électrique à ventilateur et ouvrir les évents ou les fenêtres durant quelques heures ou quelques jours. 


\section{Classement et terminologie}

Le Canadian Gladiolus Society classe les fleurs selon un code à trois chiffres. Le premier chiffre représente la grandeur des fleurs, le deuxième, la couleur de fond et le troisième, l'intensité de la couleur. La saison de floraison est indiquée par des abréviations: T.H., très hâtif; H., hâtif; H.M., hâtif mi-saison; T.M., tardif mi-saison; T., tardif. Les variétés haut cotées sont inscrites chaque année dans les Annales de la Société. On peut en obtenir un exemplaire en s'adressant au secrétaire-archiviste.

Outre les variétés bien connues à grandes fleurs et à fleurs géantes, les hybrides à petites fleurs sont de plus en plus appréciés. Ils conviennent mieux aux petits jardins d'aujourd'hui, et bon nombre de fleuristes sont d'avis que leurs inflorescences plus délicates s'harmonisent mieux avec les autres fleurs dans les compositions florales.

Le glaïeul est souvent décrit d'après la forme et la couleur de son inflorescence. Voici quelques expressions courantes:

maculée, couleur plus claire ou plus foncée en forme de coeur à l'intérieur de la gorge ou sur le bord inférieur ou interne des pétales.

striée, lignes colorées contrastant délicatement avec la couleur de fond des pétales. ponctuée, l'extrémité des pétales se prolonge en une pointe effilée et proéminente. frangée, le bord des pétales est crêpé ou plissé.

\section{Culture de fleurs destinées aux expositions}

Lorsqu'on cultive des plants en vue de les présenter aux expositions locales, on cherche à produire des fleurs de qualité supérieure. Dès la plantation des cormus, il faut tenir compte de plusieurs facteurs. Choisir un sol profond et bien drainé. Utiliser des cormus de gros calibre et, pour chaque variété, choisir les cormus d'âge à produire les plus belles inflorescences. Planter des cormus de qualité supérieure, espacés de 25 à $40 \mathrm{~cm}$, arroser suffisamment et appliquer l'engrais approprié. Veiller à ce que les plants soient dressés au cours de la saison de végétation; lorsque les épis commencent à pointer, tuteurer les plants, surtout s'ils sont exposés au vent.

On peut normalement récolter les fleurs de 60 à 100 jours après la plantation, selon la variété et les conditions météorologiques. Il faut planter les variétés tardives très tôt (ou faire germer les cormus à l'intérieur avant de les planter) et les autres variétés à deux ou trois dates de plantation, espacées de 10 jours. La cueillette des inflorescences de glaïeul s'effectue d'habitude lorsqu' un ou deux bourgeons floraux inférieurs de l'épi sont ouverts. Placer les hampes florales coupées dans environ $10 \mathrm{~cm}$ d'eau fraîche et les conserver au frais. L'épi atteindra le plein épanouissement en l'espace de 2 à 3 jours. Si les fleurs destinées à une exposition s'épanouissent trop tôt, vous pouvez les entreposer au froid, à une température de 4 à $6^{\circ} \mathrm{C}$.

Chacune des fleurs de l'épi doit être tournée du même côté et être espacée également. Dès que les épis sont développés, certains exposants commencent à les «dresser» pour s'assurer que, lorsque les fleurs s'épanouiront, elles seront disposées correctement et seront orientées dans la bonne direction. Pour corriger la 
disposition des fleurs sur l'épi, il suffit d'insérer des tampons d'ouate entre la base de la fleur et la tige. Le transport des hampes florales au lieu de l'exposition doit se faire avec grand soin, les hampes étant de préférence en position dressée pour éviter de crochir les tiges. Il importe de ne pas endommager les pétales.

Arrivé au lieu de l'exposition, débarrasser les fleurs des tampons d'ouate et corriger une dernière fois la disposition des fleurs. S'assurer que le spécimen est bien inscrit dans la bonne catégorie. Le North American Gladiolus Council a publié des normes d’appréciation du glaïeul. Les glaïeuls sont classés en cinq groupes suivant la taille de la première fleur (fleur inférieure) de l'épi. Chaque groupe de glaïeul doit satisfaire à certaines exigences. Les exposants peuvent participer à des concours pour un, trois ou cinq épis. Le résumé des normes précitées est donné dans la publication $\mathrm{n}^{\circ} 1395$ d’Agriculture Canada, intitulée «Normes d'appréciation pour expositions horticoles». Pour de plus amples renseignements sur les expositions, il suffit de s'adresser à la Canadian Gladiolus Society ou de devenir membre de cette société. En outre, se renseigner sur la notation qu'utilisent les juges sur leurs feuilles de pointage.

\section{INSECTES ET ACARIENS ${ }^{1}$}

Les pucerons et les thrips du glaïeul sont les insectes qui causent les plus grands dommages. On doit aussi lutter couramment contre le tétranyque à deux points et le taupin.

\section{Pucerons}

Les principales espèces de pucerons qui provoquent des dommages ou propagent des maladies virales sont le puceron du haricot. le puceron vert du pêcher, le puceron du bulbe de la tulipe, le puceron du melon et le puceron de la pomme de terre.

Les dommages qu'ils causent aux glaïeuls sont nombreux. Ils sucent la sève des plantes, ce qui provoque la déformation ou la décoloration des feuilles ou des fleurs et un ralentissement de la croissance. Des organismes pathogènes peuvent alors pénétrer dans la plante par les lésions. Tout en se nourrissant, les pucerons propagent les maladies virales; le puceron du melon, par exemple, répand la mosaïque du concombre. En outre, ces insectes sécrètent sur la feuille un liquide collant, appelé miellat, sur lequel se développe une fumagine qui dépare les plantes.

${ }^{1}$ Préparé par N.V. Tonks et H. Andison (tous deux retraités), station de recherche et de quarantaine des plantes de Saanichton, Sidney (C.-B.) 


\section{Description et cycle évolutif}

Les pucerons sont de petits insectes verts, brun rougeâtre ou noirs, à corps mou et à pattes plutôt longues. Au cours de la saison de végétation, on ne rencontre à peu près que des femelles. Elles atteignent la maturité en une période de 1 à 3 semaines et se reproduisent à un rythme rapide. De temps en temps, au cours de la saison, quelques pucerons des nouvelles générations de certaines espèces, devenus adultes et munis d'ailes, volent vers d'autres plantes.

\section{Lutte}

Les pucerons se multiplient rapidement. Il faut donc pulvériser ou poudrer les plantes d'un insecticide dès qu'ils apparaissent. Lorsque l'on multiplie les glaïeuls, il faut isoler les petits plants et les pulvériser régulièrement dès leur sortie de terre. Pour lutter contre le puceron des bulbes, il faut appliquer une poudre insecticide sur les cormus au moment de l'entreposage. Demander au spécialiste provincial de recommander des produits de traitement par poudrage ou pulvérisation.

\section{Thrips du glaïeul}

Les larves et les adultes piquent le feuillage et laissent des marques blanches ou «argentures» sur les feuilles et les boutons floraux. Les fleurs aussi sont déparées et leur croissance ne se fait plus normalement: souvent elles n'éclosent même pas. En outre, les thrips s'attaquent aux cormus entreposés.

\section{Description et cycle évolutif}

Les adultes, presque invisibles à l'œil nu, sont brun foncé et portent deux paires d'ailes délicates et frangées. Ils pondent des œufs minuscules dans les tissus de la plante. Les larves se nourrissent dans la gaine des feuilles et dans les boutons floraux, mais les adultes préfèrent les surfaces exposées. Ils se reproduisent durant toute la saison de végétation, et, dans des conditions favorables, une nouvelle génération peut éclore toutes les deux semaines. Il ne semble pas que les adultes hivernent à l'extérieur, au Canada.

\section{Lutte}

La meilleure méthode consiste à traiter les cormus immédiatement avant l'entreposage ou la plantation. Comme les adultes ailés peuvent s'introduire dans les plantations, il faut poudrer ou pulvériser les plants, au printemps et en été. avant l'apparition des fleurs.

\section{Traitement des cormus avant l'entreposage}

Une fois les cormus secs et propres, leur appliquer une poudre insecticide recommandée par le spécialiste provincial. Il n'est pas nécessaire de peler les cormus ni de les entreposer dans des contenants fermés. Après traitement. les laisser dans des plateaux ouverts pendant au moins un mois. Si l'on dispose d'une 
chambre froide, garder les cormus deux mois à $2^{\circ} \mathrm{C}$ ou trois mois à $4^{\circ} \mathrm{C}$, afin de détruire les thrips à tous les stades de leur cycle évolutif.

Traitement des cormus avant la plantation

Si l'on n`a pas traité les cormus avant l'entreposage. il faudra les immerger (pelés ou non) pendant $3 \mathrm{~h}$ dans une solution de Lysol $(60 \mathrm{~mL}$ dans $14 \mathrm{~L}$ d'eau). Les planter aussitôt après. Ce trempage détruit les thrips à tous les stades et ne retarde pas la croissance des plantes ni leur floraison. Pour lutter en même temps contre les maladies, ajouter au mélange un fongicide recommandé par le spécialiste provincial.

\section{Traitement des plants}

Pour lutter contre les thrips ailés qui peuvent venir des plantations voisines, poudrer ou pulvériser les plants. Comme le feuillage est difficile à mouiller. ajouter à la pulvérisation un adjuvant (mouillant et adhésif) approprié.

Effectuer trois traitements avant la floraison. Le premier lorsque les plants mesurent $15 \mathrm{~cm}$ et les deux autres à 10 jours d'intervalle. Si les plants ont soif, arroser d'abord, puis laisser sécher les feuilles avant d'appliquer l'insecticide.

\section{Tétranyque à deux points}

C'est par temps chaud et sec que cet acarien cause le plus de dommages. Les jeunes et les adultes sucent la sève du feuillage, ce qui provoque des mouchetures fines, blanchâtres ou jaunâtres. Les feuilles prennent un aspect pâle et maladif, puis elles brunissent et se couvrent d'une trame de soies fines.

\section{Description et cycle évolutif}

Le tétranyque adulte, d'une couleur orangée brillante, hiverne sur les plantes et les débris épars sur le sol. Durant la plus grande partie de la saison, toutefois, il est d'un jaune verdâtre pâle et porte deux points foncés bien en évidence sur le dos. Il est à peu près invisible à l'œil nu et, lorsqu'il est en groupe sur les feuilles, on a l'impression de points qui bougent sous les soies. Plusieurs générations voient le jour chaque année; les plus nombreuses apparaissent d'ordinaire en août et en septembre lorsqu'il fait un temps chaud et sec.

\section{Lutte}

Se renseigner auprès du spécialiste provincial sur les traitements par pulvérisation à employer.

\section{Taupins}

Deux espèces de taupins endommagent communément les glaïeuls. Leurs larves creusent des galeries dans les cormus et dans les feuilles naissantes immédiatement sous la surface du sol. 


\section{Description et cycle évolutif}

Les adultes sortent du sol au début du printemps et pondent dans le gazon. Les larves portent six pattes; elles sont minces, coriaces, brun jaunâtre ou rougeâtre. et mesurent environ $3 \mathrm{~cm}$. Elles vivent sous terre durant plusieurs années, se nourrissant de racines. À maturité, elles se transforment en pupes dans le sol, et les adultes émergent au printemps suivant.

\section{Lutte}

Consulter le spécialiste local quant aux mesures de lutte.

\section{Ciron des bulbes}

Le ciron des bulbes ne constitue un problème que lorsque la plantation est attaquée par la gale bactérienne. (Voir la section portant sur la gale bactérienne pour des renseignements sur les méthodes de lutte).

\section{DÉSHERBAGE ${ }^{2}$}

Il est important de désherber les plantations de glaïeuls afin de conserver l'humidité et les éléments nutritifs du sol. Certains herbicides ne présentent aucun danger et sont très employés, mais la plupart d'entre eux ne sont efficaces que contre les mauvaises herbes annuelles. Il ne faut donc pas planter de glaïeuls là où les mauvaises herbes vivaces posent un problème.

Un certain nombre d'herbicides tuent les mauvaises herbes au moment de leur germination dans la couche superficielle du sol, ce qui les élimine durant la plus grande partie de la saison. Il faut cependant que le sol soit suffisamment humide pour que l'herbicide pénètre dans la couche supérieure. Si la surface est sèche. l'irriguer par aspersion pour incorporer $1 \mathrm{~cm}$ d'eau au sol avant ou immédiatement après le traitement. Veiller à ce que l'épandage d'herbicide soit fait avant que les mauvaises herbes ne sortent de terre, car la plupart des produits n'ont que peu d'effet sur les feuilles.

\section{Choix de l'herbicide}

Les points à considérer sont les suivants:

- la persistance nécessaire de l'activité du produit:

- les espèces de mauvaises herbes présentes:

- les stades de croissance des mauvaises herbes et des glaïeuls;

- le coût du traitement.

${ }^{2}$ Préparé par R.M. Adamson (retraité), station de recherche et de quarantaine des plantes de Saanichton, Sidney (C.-B.). 
Il n'y a pas de produit universel; la plupart des herbicides s'appliquent à un type donné de sol et assurent la répression d'une population donnée de mauvaises herbes. Se renseigner sur le traitement recommandé dans sa région, au bureau provincial de renseignements agricoles le plus rapproché. Le dosage dépend du type de sol et de sa teneur en matière organique. Les doses d'emploi doivent être plus faibles sur les sols sableux et plus importantes sur les terres franches, les terres argileuses ou les sols riches en matière organique. La plupart des recommandations formulées par les ministères provinciaux de l'Agriculture indiquent le poids de produits actifs à appliquer au $100 \mathrm{~m}^{2}$. Pour calculer la quantité de produit correspondant au volume du réservoir du pulvérisateur, suivre les instructions figurant sur l'étiquette.

\section{Application de l'herbicide}

Pour assurer un traitement efficace, on doit appliquer l'herbicide au bon moment, uniformément et selon la dose recommandée. Une quantité trop forte peut endommager la plante cultivée, mais une quantité trop faible risque d'être inefficace.

Conseils sur l'épandage:

- utiliser une buse de bonne qualité, à ouverture moyenne et du type éventail;

- avancer à pas réguliers;

- maintenir la buse à une hauteur uniforme;

- pomper régulièrement, de façon à ce que la pression reste à peu près uniforme;

- brasser le mélange pendant la pulvérisation, car certains herbicides, en particulier les poudres mouillables, se déposent rapidement;

- examiner la buse de temps en temps pour s'assurer que le tamis n'est pas obstrué.

\section{MALADIES $^{3}$}

Les maladies provoquées par les champignons, les bactéries et les virus occasionnent, chaque année, des pertes considérables en production commerciale, ainsi que des déceptions à de nombreux jardiniers amateurs. On reconnaît facilement la plupart des maladies par les symptômes que présentent la plante en croissance ou les cormus ou les deux à la fois.

\section{Mesures générales de lutte}

On peut lutter contre la plupart des maladies du glaïeul ou les éliminer par des méthodes culturales appropriées et, au besoin, par l'emploi de produits chimiques.

\footnotetext{
${ }^{3}$ Révisé par R.O. Magie, Agricultural Research and Education Center, Bradenton, Floride, États-Unis, et J.H. Crossley (retraité), station de recherche et de quarantaine des plantes de Saanichton, Sidney (C.-B.)
} 


\section{Méthodes culturales}

- Avant de planter, examiner les cormus et détruire ceux qui présentent des symptômes de maladies.

- Traiter les cormus avec un fongicide recommandé.

- Planter en plein soleil, dans un sol bien égoutté, où la circulation de l'air est satisfaisante.

- Ne pas planter de glaïeuls dans le même sol plus d'une fois tous les 4 ans et, de préférence, attendre encore plus longtemps puisque certains organismes pathogènes peuvent survivre dans le sol. Si ce n'est pas possible, traiter le sol avec un produit chimique convenable et ne planter que des cormus exempts de maladie.

- Ne couper les hampes florales et ne travailler parmi les plantes que lorsqu'elles sont sèches. Tremper souvent le couteau de taille dans de l'alcool à friction ou un désinfectant similaire lors de la coupe des hampes ou des cormus.

- Arroser en imbibant le sol avec un boyau ou par des rigoles lorsque cela est possible, de façon à éviter de mouiller le feuillage. Lorsqu'une aspersion est inévitable, effectuer une pulvérisation fine et n'arroser que durant les heures matinales précédant le lever du soleil, lorsque les stomates des feuilles sont fermés, afin de diminuer le danger de propagation des bactéries.

- Faire sécher et nettoyer soigneusement les cormus aussitôt après leur récolte.

- Enlever les plantes spontanées.

- Dès que l'on constate la présence de plants malades, les enlever de la plantation et les détruire.

\section{Traitement avant la plantation}

\section{Traitement des cormus}

De préférence, traiter les cormus après la récolte, car c'est le moment où les mesures de lutte sont les plus efficaces, en particulier contre les maladies d'entreposage comme la pourriture sèche fusarienne (voir la section sur le traitement après la récolte). Si l'on ne traite pas tous les cormus et caïeux après la récolte, il faudra les poudrer ou les tremper dans un fongicide recommandé avant la plantation. Consulter le spécialiste provincial.

Si l'on utilise un traitement par trempage, laisser les cormus et les caïeux dans la solution de fongicide pendant 5 à 30 minutes. Agiter le mélange pour empêcher que la poudre ne se dépose. Si l'on choisit un traitement par poudrage, appliquer la poudre à l'extérieur en roulant les cormus dans un tonneau ou un sac fermé contenant une quantité de poudre légèrement supérieure à la dose nécessaire. Placer ensuite les cormus sur un treillis pour éliminer l'excès de poudre avant de les manipuler.

\section{Traitement du sol}

Si la plantation est atteinte de maladies, et si l'on est obligé de planter dans le même sol tous les ans, employer un insecticide et un fongicide.

Si les taupins posent un problème, consulter le spécialiste provincial (voir la section se rapportant aux taupins). 
On peut utiliser des fumigants pour lutter contre les maladies des gläeuls. Consulter le spécialiste provincial sur la nature des produits à employer, la manière de les appliquer et le temps qu’il faudra attendre avant de planter.

$\mathrm{Si}$ seule la pourriture sèche pose un problème, on peut obtenir de bons résultats en utilisant un fongicide. Se renseigner sur le fongicide recommandé dans la région et sur sa dose d'emploi, en s'adressant au spécialiste provincial. II faudra travailler le sol soigneusement afin d'incorporer le fongicide à une profondeur de $15 \mathrm{~cm}$.

\section{Pulvérisation du feuillage}

Pulvériser avec un fongicide, tous les 10 jours, dès que les plants atteignent $15 \mathrm{~cm}$ et jusqu'à ce que les boutons floraux commencent à se colorer. Pulvériser après floraison au besoin. Si le liquide n'adhère pas aux feuilles, ajouter un agent mouillant et adhésif approprié.

\section{Traitement après la récolte}

Il est plus efficace de traiter les cormus en automne, alors qu'ils sont fraîchement nettoyés, qu'avant la plantation, en particulier contre les maladies d'entrepôt telle la pourriture sèche fusarienne. Le traitement après récolte remplacera habituellement le traitement avant plantation. Prendre soin de laver les cormus dès leur récolte. Après le lavage, effectuer le traitement, puis faire sécher durant 10 à 14 jours, à une température de 29 à $32^{\circ} \mathrm{C}$. Demander au spécialiste provincial quel est le traitement à appliquer.

\section{Maladies causées par les bactéries et les champignons}

\section{Gale bactérienne}

La gale bactérienne est l'une des maladies les plus courantes du glaïeul. Elle détériore les cormus et les rend impropres à la vente. La bactérie qui provoque la gale peut survivre dans le sol pendant au moins un an et se perpétuer indéfiniment sur les plantes spontanées. La maladie se manifeste surtout dans les sols argileux ou mal drainés.

\section{Dommages}

Les parties malades du cormus sont brunâtres, déprimées et ordinairement circulaires, avec un rebord en saillie. Une substance dure et vernissée les recouvre. Par temps pluvieux et en particulier dans des sols humides, la maladie peut envahir la tige près du sol et s'étendre sur plusieurs centimètres de hauteur. De petites taches jaune brunâtre apparaissent sur les feuilles. Ces taches s'élargissent et se rejoignent pour former des surfaces nécrosées de forme allongée.

Lutte

Voir la section portant sur les méthodes culturales. Éliminer soigneusement les cormus attaqués, car les traitements chimiques ne sont pas efficaces lorsque l'infection est importante. 


\section{Pourriture botrytique}

La pourriture botrytique est très répandue en Colombie-Britannique, et c'est lorsque l'humidité est élevée qu'elle cause le plus de dommages. Lorsque l'on plante des cormus infectés, ils pourrissent ou produisent des tiges étiolées et jaunâtres qui meurent rapidement. L'infection est transmise par les spores provenant des feuilles, et non par les résidus d'une récolte précédente.

\section{Dommages}

Sur la tige, la maladie commence près du sol et produit un anneau de tissus pourris brun ou gris noir. Les feuilles infectées commencent à jaunir depuis leur extrémité jusqu'à leur base, puis meurent. Par temps frais et humide, des spores grises caractéristiques se forment sur les parties pourries. et sont transportées par le vent vers d'autres plantes. Lorsque les parties souterraines pourrissent, seules restent les fibres résistantes, et les tiges prennent une apparence déchiquetée. Le champignon peut produire des organes de repos de grande dimension sur les tiges très pourries.

Sur les feuilles, les spores en germination produisent de petites taches rondes allant du brun rougeâtre au rouille. En s'élargissant, plusieurs taches peuvent se rejoindre pour former de grandes plages dont la couleur est essentiellement brun jaunâtre, avec un centre brun clair. Par temps humide, des masses de spores grises caractéristiques se forment sur ces plages.

Des taches brunes peuvent se former sur les fleurs, les rendant impropres à la commercialisation.

Sur les cormus, les symptômes varient selon le point de départ de la maladie. Les zones d'infection superficielle sont circulaires et déprimées; les centres sont habituellement de couleur dominante jaune paille et bordés de brun rougeâtre ou de brun foncé. Lorsque l'infection est arrêtée, ces plages deviennent brunes et fermes. Les infections ayant leur point d'origine à la sommité de la tige ou à la base des cormus provoquent la pourriture du cœur de ces derniers. Cette pourriture peut gagner la surface; toutefois, si elle est arrêtée avant, le cœur peut tomber ou se désagréger, le cormus prenant alors la forme d'un anneau.

Les cormus infectés, même s'ils sont convenablement séchés, continuent à pourrir lorsqu'ils sont entreposés au froid. Le cormus tout entier peut devenir mou, spongieux et brun foncé. On peut prévenir cette pourriture des cormus infectés en les entreposant à une température supérieure à $13^{\circ} \mathrm{C}$. Aux températures plus élevées, les cormus ont tendance à résister à l'infection.

Lutte

Voir la section portant sur les méthodes culturales. La maladie évolue rapidement lorsque l'air est humide et frais. Quelles que soient les conditions ambiantes, éliminer toutes plantes ou couper immédiatement les parties atteintes afin d'empêcher la propagation de la maladie. On peut également tremper les cormus dans une solution de fongicide avant la plantation. Dans les régions où la pourriture botrytique est fréquente, pulvériser sur le feuillage un produit recommandé par le spécialiste provincial. 


\section{Pourriture sclérotique}

La pourriture sclérotique est une maladie très répandue chez les glaieuls. Elle s'attaque aux plantes en pleine terre aussi bien qu'aux cormus en entrepôt, et provoque des pertes considérables, en particulier dans les régions à proximité de la côte du Pacifique. Dans les plantations, la pourriture sclérotique cause des dommages plus graves en saison humide qu'en saison sèche.

\section{Dommages}

Les symptômes les plus caractéristiques se manifestent sur les feuilles au cours de la croissance. Les feuilles près du sol sont atteintes les premières; elles jaunissent à partir de leur extrémité jusqu'à leur base, alors que la gaine et la tige brunissent puis noircissent. Par la suite, la gaine s'effiloche et se couvre de nombreux organes de repos noirs et ronds, tout juste visibles à l'œil nu. La présence de ces organismes minuscules et l'absence de masses de spores grises distingue cette maladie de la pourriture botrytique de la tige.

Sur les cormus, la pourriture apparait d'abord sous forme de petits points brun rougeâtre caractéristiques. Ces points sèchent et deviennent brun foncé ou noirs avec des rebords légèrement en saillie, et leur taille varie de la grosseur d'une pointe d'épingle à $6 \mathrm{~mm}$ de diamètre. Plusieurs taches peuvent se fusionner pour former des plages irrégulières. Ces taches s'observent surtout le long des lignes de nœud, et en général, à leur partie supérieure. Lorsque des cormus infectés sont plantés ou entreposés, la pourriture s'étend à l'intérieur et ils finissent par devenir durs et noirs.

En plantant des cormus légèrement infectés dans un sol sain, on y introduit le champignon qui peut survivre pendant plusieurs années même si l'on n'y cultive pas de glaïeuls.

Lutte

Voir la section portant sur les méthodes culturales. Enlever les cormus infectés afin d'éviter d'introduire la maladie dans un sol sain. Si le sol est contaminé, ne pas planter de glaïeuls pendant 4 ou 5 ans, ou procéder à des traitements chimiques. Consulter le spécialiste provincial au sujet des produits à utiliser pour le traitement du sol. Afin de prévenir une nouvelle infection, traiter les cormus par trempage ou poudrage, suivant les indications du spécialiste provincial.

\section{Jaunisse fusarienne}

La jaunisse fusarienne est provoquée par un champignon qui peut vivre dans le sol pendant plusieurs années. Une température élevée du sol et le manque d'humidité favorisent la maladie. Il s'agit surtout d'une maladie de plein champ. mais les cormus infectés dans le sol qui sont ultérieurement récoltés peuvent continuer à pourrir en entrepôt.

\section{Dommages}

Les premiers symptômes se manifestent avec le temps chaud. Les plants attaqués cessent de croître et ont une taille nettement inférieure à la normale. Les feuilles deviennent jaunes à partir de leur extrémité ou de leurs bords, puis elles brunissent et meurent. Il n'y a pas de zones noircies à la base des feuilles. 
Les cormus s'infectent à partir de bulbes malades qui sont soit simplement un peu brunis ou complètement pourris. Une pourriture brune apparaît à la base des cormus infectés. Leurs cœurs sont également bruns, et des stries rayonnent dans les tissus avoisinants. Les cormus peuvent même finir par pourrir complètement.

\section{Lutte}

Pour atteindre une efficacité optimale, il faut employer plusieurs méthodes de lutte, y compris traiter les caïeux et les cormus à l'eau chaude et par des produits chimiques, et atténuer l'infestation du sol en pratiquant une rotation des cultures d'une période de 6 à 10 ans ou en fumigant. Traiter les cormus en les trempant ou en les poudrant avant la plantation. Consulter le spécialiste provincial quant au produit chimique à utiliser dans la région. Le traitement décrit ci-après est efficace pour les caïeux.

Arracher les caïeux de bonne heure, les conserver à la température ambiante (de 18 à $23^{\circ} \mathrm{C}$ ) pendant 8 à 10 semaines, puis les tremper dans de l'eau pendant $24 \mathrm{~h}$, et éliminer ceux qui flottent. Placer ensuite les bons caïeux (ceux qui sont submergés) pendant 30 min dans de l'eau maintenue à $56^{\circ} \mathrm{C}$, à laquelle on aura ajouté un fongicide. Le spécialiste provincial pourra recommander un fongicide convenant à la région. Agiter la solution tout en veillant à ce que la température demeure constante tout au long de la période de trempage. Faire sécher les caïeux et les conserver dans un entrepôt frais $\left(\right.$ de 2 à $\left.4^{\circ} \mathrm{C}\right)$ jusqu'à deux semaines avant la plantation. Si l'on trempe les caïeux dans de l'eau avant la plantation, les traiter de nouveau avec un fongicide.

\section{Pourriture pénicillienne}

La pourriture pénicillienne endommage surtout les cormus en entrepôt. Le cryptogame pénètre par les blessures subies dans le champ ou en entrepôt. La maladie ne devient grave que lorsque les cormus ne sont pas convenablement séchés.

\section{Dommages}

Les zones atteintes sont brun rougeâtre, déprimées, irrégulières et ratatinées. À l'air humide, les masses de spores bleu vert prolifèrent en surface. Des organes de repos du champignon, de couleur brun clair ou chamois, peuvent se développer dans les tissus. La pourriture humide peut se répandre dans les cormus et finir par les détruire.

Lutte

Consulter la section portant sur les méthodes culturales. Prendre soin de ne pas blesser les cormus lors de la récolte et du nettoyage. Les faire sécher rapidement afin d'empêcher la propagation de la maladie. Avant de les entreposer. les poudrer d'un fongicide recommandé par le spécialiste provincial.

\section{Brûlure des feuilles (Stemphylium)}

La brûlure des feuilles s'attaque parfois aux glaïeuls en ColombieBritannique. Elle se manifeste le plus fréquemment par temps humide. et c'est au moment de la floraison qu'elle est la plus destructrice. 


\section{Dommages}

La maladie provoque sur les feuilles de petites taches rondes, jaune pâle et translucides. Le centre des taches devient rouge ou brun rougeâtre. d'où le deuxième nom donné à cette maladie: «tache rouge». Lorsque les feuilles sont fortement attaquées, les plantes sont rabougries et les cormus petits.

Lutte

Si la maladie prend de l'ampleur, traiter les plantes par pulvérisation du feuillage.

\section{Maladies virales}

Les cormus cultivés au Canada de même que les cormus importés sont de plus en plus atteints de maladies virales. Les symptômes sont souvent confondus avec ceux d'une carence en éléments nutritifs ou avec les dommages causés par les insectes, le thrips par exemple. Les symptômes peu apparents peuvent souvent sembler sans importance, mais, d'une année à l'autre, on constatera une dégradation de la qualité et de la vigueur des plants infectés. L'infection peut se propager à tous les plants d'une culture.

\section{Dommages}

Les maladies virales peuvent provoquer des marbrures ou des stries blanc jaunâtre sur les feuilles, ainsi que des rayures ou des taches blanchâtres sur les pétales. Les feuilles peuvent prendre une couleur bronze ou virer au jaune, en même temps que les boutons floraux et les pétales deviennent verdâtres; ou bien les feuilles peuvent rester minces et les plantes cesser de fleurir. Les vecteurs des virus qui provoquent les symptômes susnommés sont des insectes qui transportent ces virus à partir d'autres glaïeuls ou de plantes d'espèces différentes. En règle générale, aucun symptôme n'est visible sur les cormus malades.

\section{Lutte}

Détruire les plants présentant l'un de ces symptômes si l'on ne peut, par ailleurs, associer ces derniers à une maladie cryptogamique ou à la présence d'insectes parasites, car les plantes envahies par un virus ne peuvent être guéries. Prendre grand soin d'éliminer les pucerons et les cicadelles pour les empêcher de répandre les maladies. Étant donné que certains virus qui s'attaquent aux glaïeuls (en particulier ceux de la mosaïque jaune du haricot et de la tache annulaire du tabac) peuvent être propagés par les outils utilisés pour couper les fleurs, il faut après chaque coupe tremper les instruments dans une solution stérilisante comme l'orthophosphate trisodique à $10 \%$ ou l'alcool méthylique à $25 \%$. Le désherbage constitue aussi une bonne méthode de lutte contre les maladies à virus. 


\section{REMERCIEMENTS}

Nous remercions les personnes suivantes de nous avoir fourni de précieux renseignements sur la culture du glaïeul: W. Kempster, Sidney (C.-B.): R. Mills, Regina (Sask.); H.F. Harp, ferme expérimentale, Morden (Man.); B. Peturson, Université du Manitoba, Winnipeg (Man.); R.A. Fleming, station expérimentale horticole, Vineland (Ont.): et J.H. Crossley (retraité), station de recherche et de quarantaine des plantes de Saanichton, Sidney (C.-B.).

\section{NOMS SCIENTIFIQUES}

\section{Insectes et acariens}

Ciron des bulbes

Puceron du bulbe de la tulipe

Puceron du haricot

Puceron du melon

Puceron vert du pêcher

Puceron de la pomme de terre

Taupins

Tétranyque à deux points

Thrips du glaïeul

\section{Maladies}

Brûlure des feuilles (Stemphylium) Gale bactérienne

Jaunisse fusarienne

Pourriture botrytique

Pourriture pénicillienne

Pourriture sclérotique
Rhizoglyphus echinopus (Fumouze \& Robin)

Dysaphis tulipae (Fonscolombe)

Aphis fabae Scopoli

Aphis gossypii Glover

Myzus persicae (Sulzer)

Macrosiphum euphorbiae (Thomas)

Agriotes sparsus LeConte

Ctenicera aeripennis (Kirby)

Tetranychus urticae Koch (T. telarius des auteurs)

Taeniothrips simplex (Morison)
Stemphylium sp.

Pseudomonas marginata (McCull.)

Stapp

Fusarium oxysporum Schlecht. f. sp. gladioli (Massey) Snyd. \& Hans.

Botrytis gladiolorum Timmerm.

Penicillium gladioli McCull. \& Thom Stromatinia gladioli (Drayton) Whet. 


\section{FACTEURS DE CONVERSION}

Unité métrique

Facteur

approximatif

LINEEAIRE

millimètre $(\mathrm{mm})$

centimètre $(\mathrm{cm})$

de conversion

Donne

mètre $(\mathrm{m})$

kilomètre $(\mathrm{km})$

$\times 0,04$

$\times 0,39$

pouce

$\times 3,28$

pouce

pied

$\times 0,62$

mille

\section{SUPERFICIE}

centimètre carré $\left(\mathrm{cm}^{2}\right)$

$x 0,15$

mètre carré $\left(\mathrm{m}^{2}\right)$

$\times 1,2$

$\times 0.39$

hectare (ha)

$\times 2,5$

verge carrée

mille carré

acre

\section{VOLUME}

centimètre cube $\left(\mathrm{cm}^{3}\right)$

$\times 0,06$

$\times 35,31$

mètre cube $\left(\mathrm{m}^{3}\right)$

$\times 1,31$

\section{CAPACITÉ}

litre (L)

hectolitre $(\mathrm{hL})$

$\times 0,035$

$\times 22$

$\times 2,5$

POIDS

gramme (g)

kilogramme $(\mathrm{kg})$

tonne ( $t$ )

$\times 0,04$

$\times 2,2$

$\times 1,1$

pouce cube

pied cube

verge cube

\section{AGRICOLE}

litres à I'hectare

$\times 0,089$

$\times 0,357$

$\times 0,71$

millilitres à I'hectare

$\times 0,014$

tonnes à l'hectare

$\times 0,45$

kilogrammes à l'hectare

$\times 0,89$

pied cube

gallons

boisseaux

grammes à I'hectare

$\times 0,014$

plants à l'hectare

$\times 0,405$

once

livre

tonne courte

gallons à l'acre

pintes à l'acre

chopines à l'acre

onces liquides à

l'acre

tonnes à l'acre

livres à l'acre

onces à l'acre

plants à l'acre 
$\begin{array}{lll}3 & 9073 \quad 00027131,4\end{array}$ 
